Eric C. Hosten and Richard Betz*

\title{
The crystal structure of para-nitrobenzylbromide, $\mathrm{C}_{7} \mathrm{H}_{6} \mathrm{BrNO}_{2}-\mathrm{A}$ second polymorph and correction of $3 \mathrm{D}$ coordinates
}

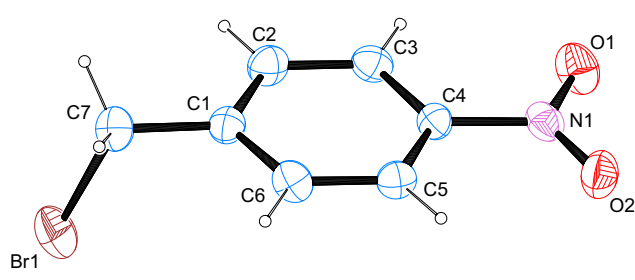

https://doi.org/10.1515/ncrs-2020-0564

Received November 1, 2020; accepted December 14, 2020; published online February 12, 2021

\section{Abstract \\ $\mathrm{C}_{7} \mathrm{H}_{6} \mathrm{BrNO}_{2}$, orthorhombic, $P 2_{1} 2_{1} 2_{1}$ (no. 19), $a=4.7019(6) \AA$, $b=6.4700(9) \AA ̊ ., c=25.283(4) \AA, V=769.14(19) \AA^{3}, Z=4$, $R_{g t}(F)=0.0294, w R_{\text {ref }}\left(F^{2}\right)=0.0671, \mathrm{~T}=200 \mathrm{~K}$.}

\section{CCDC no.: 2050071}

The molecular structure is shown in the Figure. Table 1 contains crystallographic data and Table 2 contains the list of the atoms including atomic coordinates and displacement parameters.

\section{Source of material}

The compound was obtained commercially (Merck). Crystals suitable for the diffraction study were taken directly from the provided product.

\section{Experimental details}

Carbon-bound $\mathrm{H}$ atoms were placed in calculated positions (C-H $0.95 \AA$ for aromatic carbon atoms, C-H $0.99 \AA$ for

*Corresponding author: Richard Betz, Department of Chemistry, Nelson Mandela University, Summerstrand Campus (South), University Way, Summerstrand, P.0. Box 77000, Port Elizabeth 6031, South Africa, E-mail: Richard.Betz@mandela.ac.za. https://orcid. org/0000-0002-5730-2152

Eric C. Hosten, Department of Chemistry, Nelson Mandela University, Summerstrand Campus (South), University Way, Summerstrand, P.O. Box 77000, Port Elizabeth 6031, South Africa. https://orcid.org/ 0000-0003-4173-2550
Table 1: Data collection and handling.

\begin{tabular}{|c|c|}
\hline Crystal: & Colourless rod \\
\hline Size: & $0.38 \times 0.12 \times 0.11 \mathrm{~mm}$ \\
\hline Wavelength: & Mo $K \alpha$ radiation $(0.71073 \AA$ ) \\
\hline$\mu:$ & $5.29 \mathrm{~mm}^{-1}$ \\
\hline Diffractometer, scan mode: & Bruker APEX-II, $\varphi$ and $\omega$ \\
\hline$\theta_{\max }$, completeness: & $28.0^{\circ}, 99 \%$ \\
\hline$N(h k l)_{\text {measured }}, N(h k l)_{\text {unique }}, R_{\text {int }}:$ & $6983,1854,0.035$ \\
\hline Criterion for $I_{\mathrm{obs}}, N\left(h k l_{\mathrm{gt}}\right.$ : & $I_{\text {obs }}>2 \sigma\left(I_{\text {obs }}\right), 1583$ \\
\hline$N(\text { param })_{\text {refined }}:$ & 101 \\
\hline Programs: & $\begin{array}{l}\text { Bruker [1, 2], SHELX [3], } \\
\text { WinGX/ORTEP [4], Mercury [5], } \\
\text { PLATON [6] }\end{array}$ \\
\hline
\end{tabular}

Table 2: Fractional atomic coordinates and isotropic or equivalent isotropic displacement parameters $\left(\AA^{2}\right)$.

\begin{tabular}{lrrrr}
\hline Atom & $\boldsymbol{x}$ & $\boldsymbol{y}$ & $\boldsymbol{z}$ & $\boldsymbol{U}_{\text {iso }}{ }^{*} \boldsymbol{U}_{\text {eq }}$ \\
\hline Br1 & $1.23357(10)$ & $0.04014(6)$ & $0.22432(2)$ & $0.04408(15)$ \\
O1 & $0.5682(6)$ & $0.8376(4)$ & $0.06872(10)$ & $0.0376(7)$ \\
O2 & $0.5052(6)$ & $0.5864(4)$ & $0.01375(10)$ & $0.0357(7)$ \\
N1 & $0.6222(7)$ & $0.6632(5)$ & $0.05236(12)$ & $0.0275(7)$ \\
C1 & $1.2296(8)$ & $0.3067(5)$ & $0.13533(12)$ & $0.0243(7)$ \\
C2 & $1.1623(8)$ & $0.5066(6)$ & $0.15216(14)$ & $0.0297(9)$ \\
H2 & 1.252854 & 0.562323 & 0.182576 & $0.036^{*}$ \\
C3 & $0.9648(8)$ & $0.6240(6)$ & $0.12488(13)$ & $0.0271(8)$ \\
H3 & 0.917248 & 0.759395 & 0.136447 & $0.033^{*}$ \\
C4 & $0.8378(7)$ & $0.5399(5)$ & $0.08028(13)$ & $0.0230(7)$ \\
C5 & $0.9028(8)$ & $0.3436(6)$ & $0.06217(13)$ & $0.0256(8)$ \\
H5 & 0.814296 & 0.289823 & 0.031330 & $0.031^{*}$ \\
C6 & $1.0993(8)$ & $0.2277(5)$ & $0.08992(13)$ & $0.0270(8)$ \\
H6 & 1.146351 & 0.092666 & 0.078011 & $0.032^{*}$ \\
C7 & $1.4360(8)$ & $0.1792(6)$ & $0.16603(13)$ & $0.0305(8)$ \\
H7A & 1.588254 & 0.268503 & 0.180481 & $0.037^{*}$ \\
H7B & 1.524724 & 0.074905 & 0.142606 & $0.037^{*}$ \\
\hline
\end{tabular}

methylene groups) and were included in the refinement in the riding model approximation, with $U(\mathrm{H})$ set to $1.2 U_{\text {eq }}(\mathrm{C})$.

The compound was refined as a two-component inversion twin with a volume ratio of 94.4:5.6. 


\section{Comment}

Benzylic halogenides are versatile synthons in Organic Chemistry. Resonance effects greatly assist in displacing the halogen atom in the wake of nucleophilic substitution reactions [7]. A vast series of such derivatives bearing functional groups on the aromatic system has been synthesized and characterized over the last century. In continuation of our interest in the structural chemistry of halogenated derivatives of benzene [8-16] the molecular and crystal structure of the title compound were determined. While a structural analysis is apparent in the literature (ref. Code: WIQDUV) [17], the latter is plagued by two problems: first, the structure was determined based on powder diffraction data which precludes the anisotropic treatment of the atoms during the refinement procedure and - second - an inspection of the 3D coordinates reveals a number of questionable features such as an undulated aromatic system, involving the pertaining hydrogen atoms to create linear zig-zag patterns. Furthermore, the cell constants found in this study differ from the ones reported earlier [17]. The molecular and crystal structure of the chlorinated equivalent have been determined previously $[18,19]$.

The title crystal solution shows the presence of 4-nitrobenzylbromide. The $\mathrm{C}-\mathrm{Br}$ bond length of 1.971(4) $\AA$ and the nearly equal $\mathrm{N}-\mathrm{O}$ bond lengths of 1.226(4) and 1.228 (4) $\AA$ are in good agreement with pertaining values found for other comparable compounds whose metrical parameters have been deposited with the Cambridge Structural Database [20]. Intracyclic C-C-C angles span a range of $118.6(3)^{\circ}-122.3(3)^{\circ}$ with the smaller value being present on both carbon atoms in ortho-position to the nitro group and the largest value on the carbon atom bearing the latter substituent. The least-squares planes as defined by the respective atoms of the nitro group and the nonhydrogen atoms of the bromomethyl group and its pertaining ipso-carbon atom enclose angles of $2.0(4)^{\circ}$ and $84.8(3)^{\circ}$, respectively, with the first value being indicative of resonance involving the nitro group.

In the crystal, $\mathrm{C}-\mathrm{H} \cdots \mathrm{O}$ contacts whose range falls by more than 0.1 A below the sum of van-der-Waals radii of the atoms participating in them. These are established between one of the hydrogen atoms of the methylene group as well as one of the aromatic $\mathrm{CH}$ groups in ortho-position to the halogenated substituent and one of the oxygen atoms of the nitro group as acceptor. In terms of graph-set analysis [21, 22], the descriptor for these contacts is $C_{1}^{1}(6) C_{1}^{1}$ ( 8) on the unary level. In total, the molecules are connected to chains along [110]. One could discuss a possible $\mathrm{C}-\mathrm{H} \cdots \pi$ interaction, however, the latter is characterized by an angle deviating strongly from linearity. $\pi$-Stacking is not a prominent feature in the crystal structure of the title compound with the shortest distance found between two centers of gravity measured at 4.702(2) A.

Author contribution: All the authors have accepted responsibility for the entire content of this submitted manuscript and approved submission.

Research funding: The corresponding author thanks the National Research Foundation for financial support.

Conflict of interest statement: The authors declare no conflicts of interest regarding this article.

\section{References}

1. Bruker. APEX2; Bruker AXS Inc.: Madison, Wisconsin, USA, 2012.

2. Bruker. $S A D A B S$; Bruker AXS Inc.: Madison, Wisconsin, USA, 2008.

3. Sheldrick G. M. A short history of SHELX. Acta Crystallogr. 2008, A64, 112-122.

4. Farrugia L. J. WinGX and ORTEP for Windows: an update. J. Appl. Crystallogr. 2012, 45, 849-854.

5. Macrae C. F., Bruno I. J., Chisholm J. A., Edgington P. R., McCabe P., Pidcock E., Rodriguez-Monge L., Taylor R., van de Streek J., Wood P. A. Mercury CSD 2.0 - new features for the visualization and investigation of crystal structures. J. Appl. Crystallogr. 2008, 41, 466-470.

6. Spek A. L. Structure validation in chemical crystallography. Acta Crystallogr. 2009, D65, 148-155.

7. Becker H. G. O., Beckert R., Domschke G., Fanghänel E., Habicher W. D., Metz P., Pavel D., Schwetlick K. Organikum Organisch-Chemisches Grundpraktikum, 21st ed.; Wiley-VCH: Weinheim, 2000.

8. Betz R., McCleland C., Glover S. 2-(4-Iodophenoxy)acetamide. Acta Crystallogr. 2011, E67, 01928.

9. Betz R., Klüfers P. 1-Bromomethyl-2-iodobenzene. Acta Crystallogr. 2007, E63, 04753.

10. Betz R., Klüfers P. 2-Iodobenzaldehyde. Acta Crystallogr. 2007, E63, 04879.

11. Betz R., Gerber T. 2-Chloro-6-fluorobenzoic acid. Acta Crystallogr. 2011, E67, 01329.

12. Schmitt B., Gerber T., Hosten E., Betz R. 4-Bromobenzoyl 4-bromobenzoate monohydrate. Acta Crystallogr. 2011, E67, 01662.

13. Betz R., Klüfers P. N-(2-lodophenylmethyl) hexamethylenetetraminium bromide dihydrate. Acta Crystallogr. 2007, E63, 04279.

14. Betz R., Klüfers P. 2,4,6-Trifluoroaniline. Acta Crystallogr. 2008, E64, 02242.

15. Betz R., Gerber T. 2,4,6-Trifluorobenzoic acid. Acta Crystallogr. 2011, E67, 0539.

16. Vijesh A. M., Isloor A. M., Gerber T., van Brecht B., Betz R. 1,5-Dibromo-2,4-dimethoxybenzene. Acta Crystallogr. 2012, E68, 03479.

17. Goubitz K., Sonneveld E. J., Chernyshev V. V., Yatsenko A. V., Zhukov S. G., Reiss C. A., Schenk H. Crystal structure 
determination of a series of benzene derivatives from powder data. Z. Kristallogr. Cryst. Mater. 1999, 214, 469-474.

18. Aziz-ur-Rehman A., Yasir A., Akkurt M., Abbasi M. A., Jahangir M., Khan I. U. 1-Chloromethyl-4-nitrobenzene. Acta Crystallogr. 2010, E66, 01667.

19. Betz R., Britten-Kelly M., McCleland C., Hosten E. Refinement of the crystal structure of 1-chloromethy 1-nitrobenzene, $\mathrm{C}_{7} \mathrm{H}_{6} \mathrm{CINO}_{2}$, at $200 \mathrm{~K}$. Z. Kristallogr. NCS 2011, 226, 583-584.
20. Allen F. H. The Cambridge Structural Database: a quarter of a million crystal structures and rising. Acta Crystallogr. 2002, B58, 380-388.

21. Bernstein J., Davis R. E., Shimoni L., Chang N.-L. Patterns in hydrogen bonding: functionality and graph set analysis in crystals. Angew Chem. Int. Ed. Engl. 1995, 34, 1555-1573.

22. Etter M. C., MacDonald J. C., Bernstein J. Graph-set analysis of hydrogen-bond patterns in organic crystals. Acta Crystallogr. 1990, B46, 256-262. 